\title{
Effect of Silver Nanoparticles on Aquatic Organisms
}

\author{
Ranjitha Thimmegowda $1, *$ (D) \\ 1 Department of Civil Engineering, LV Polytechnic College, Hassan, India \\ * Correspondence: ranjithacivil23@gmail.com;
}

Received: 22.08.2020; Revised: 1.10.2020; Accepted: 3.10.2020; Published: 6.10.2020

\begin{abstract}
Silver nanoparticles are extensively used in the past few years. The presence of these silver nanoparticles concerns the risks they pose to the environment as a whole. Their tiny size and higher surface area make them a very potent threat in the aquatic ecosystem. The interactions and bioaccumulation in the aquatic ecosystem have led to disturbances in the food chain of the aquatic organism. The silver nanoparticles have caused biochemical, physiological, morphological, and neurological impairment in the aquatic organisms. There are several studies that not only report the direct impact of these AgNPs on the water bodies but also report the impact of ligand-bound AgNPs on aquatic invertebrates at different trophic levels and different medium. This literature review attempts to integrate recent findings on the impact of silver nanoparticles and associated studies on aquatic organisms.
\end{abstract}

Keywords: ecosystem, environment, morphology, toxicity.

(C) 2020 by the authors. This article is an open-access article distributed under the terms and conditions of the Creative Commons Attribution (CC BY) license (https://creativecommons.org/licenses/by/4.0/).

\section{Introduction}

Silver and silver nanoparticles (AgNPs), along with other toxic chemicals such as mercury, cadmium, chromium, copper, are considered as one of the most toxic heavy metals [1,2,3]. Silver in metallic form is known to have minimal toxic effects [4]. However, silver ions are reported to be more deleterious as they are non-biodegradable, very chemically unstable. Thus, they are a significant toxicant in the aquatic ecosystem, which also impacts human health $[5,6,7]$. The occurrence of silver ions and silver nanoparticles is a serious health risk [8]. The bioaccumulation of silver nanoparticles in the aquatic ecosystem results in irreversible damage and disorders [9]. The interaction of nanoparticles to aquatic organisms leads to severe disturbances [10]. Nanoparticles enter the fish and thus become a part of the food cycle in aquifers [11]. The minute size and enhanced surface area of silver nanoparticles bind strongly to living organisms leading to toxic effects [12].

In this direction, we attempted to make a literature review of recent developments in the interaction of silver nanoparticles with the aquatic ecosystem in this article.

\section{Observations}

One study [13] reported silver nanoparticles' toxicity on marine macroalgae Ulva rigida C. Agardh (1823). They observed the silver bioaccumulation, chloroplast ultrastructure damage, neutral lipid production, and oxidative stress upon exposure to silver nanoparticles. The toxic effects of silver nanoparticles were reported at $0.1 \mathrm{ppm}$ and induced lipid peroxidation. They concluded that silver nanoparticles' toxicity on marine macroalgae could be mitigated by enhanced natural ligand content of the transitional environment. 
Pham et al. [14] reported silver nanoparticles' interaction on two tropical microalgae species, freshwater Scenedesmus sp and marine diatom Thalassiosira sp. The results proposed that silver nanoparticles displayed dual toxicity outcomes on microalgae, with higher toxicity in freshwater than the marine ecosystem. AgNPs at particular doses have exhibited cell diameter changes, lowering of chlorophyll content, and an increase in total lipid production in the microalgae.

A study [15] reports the effect of silver nanoparticles on freshwater snail Physa acuta. The study proposed that the increase in acute toxicity was coupled with the decrease of shell length in the snail exposed to AgNPs, with juveniles being more susceptible. Chronic exposure demonstrated that the hatching process was also vulnerable. Finally, it was concluded that silver nanoparticles distort the life cycle of the snail.

Surface properties are decisive in the interaction of silver nanoparticles in the aquatic ecosystem. In this regard, findings have been reported [16], where ligand tagged AgNPs, Tyrosine (T-AgNP), curcumin (C-AgNP), and epigallocatechin gallate (E-AgNP) and their effect on the aquatic organism Daphnia carinata. The reports proposed how ligand coatings guided silver nanoparticles' outcomes on the mortality, feeding behavior, bioaccumulation from freshwater algae Raphidocelis subcapitata to Daphnia carinata. The results suggested that silver nanoparticles' bioaccumulation in freshwater algae and ligand-bound bioaccumulation of silver nanoparticles in Daphnia carinata changed for all three separately ligands tagged silver nanoparticles. Curcumin AgNPs accumulation was 1.5 times higher in algae than tyrosine AgNPs. But the bioaccumulation of T AgNPs in Daphnia carinata through trophic transfer was 2.6 times more than T-AgNPs in algae. Thus the results [16] help understand the impact of silver nanoparticles and their surface properties concerning aquatic organisms.

The effects of silver nanoparticles at different trophic levels and life strategies in separate media are reported [17]. The toxicity of tyrosine tagged silver nanoparticles on three Australian freshwater invertebrates, namely Daphnia carinata, Paratya australiensis, and Hydra vulgaris are reported [17, 18, 19]. The above study reported the notable variations in silver nanoparticle toxicity to aquatic organisms [17-20] is present and coupled with a significant role by test media and life strategies. The research group [17] proposed that the multispecies approach can be adapted to predict nanoparticles' risk and thus protect the indigenous aquatic species from interactions with toxic materials [21,22,23].

\section{Conclusions}

Several studies have confirmed the toxicity of silver nanoparticles on the aquatic ecosystem and thus on aquatic organisms. Different invertebrates in the aquatic environment are affected by the biological interaction and bioaccumulation of these AgNPs. There are several measures suggested by many study groups to ameliorate the toxicity of AgNPs. Toxicity assessment, understand the native ecosystem are some of them. To conclude, the policy-making authorities and the key stakeholders in the related sector have made serious decisions to avoid a future toxic outbreak in the aquatic environment due to the accumulation of silver nanoparticles.

\section{Funding}

This research required no external funding. 


\section{Acknowledgments}

The author has no acknowledgments to make.

\section{Conflicts of Interest}

The authors declare no conflict of interest.

\section{References}

1. Rashmi, N.; Ranjitha, T.; Sp, S.C. Chromium and their Derivatives Causes Physiological and Biochemical Modifications in Diverse Fish Models: A Review. Biomedical and Pharmacology Journal 2019, 12, 20492053, https://doi.org/10.13005/bpj/1838.

2. Doudoroff, P.; Katz, M. Critical review of literature on the toxicity of industrial wastes and their components to fish: II. the metals, as salts. Sewage and Industrial Wastes 1953, 802-839

3. Albright, L.J.; Wentworth, J.W.; Wilson, E.M. Technique for measuring metallic salt effects upon the indigenous heterotrophic microflora of a natural water. Water Res. 1972, 6, 1589-159, https://doi.org/10.1016/0043-1354(72)90083-8.

4. Drake, P.L.; Hazelwood, K.J. Exposure-related health effects of silver and silver compounds: a review. The Annals of occupational hygiene 2005, 49, 575-585, https://doi.org/10.1093/annhyg/mei019.

5. Eckelman, M.J.; Graedel, T.E. Silver Emissions and their Environmental Impacts: A Multilevel Assessment. Environ. Sci. Technol. 2007, 41, 6283-6289, https://doi.org/10.1021/es062970d.

6. Ranjitha, T.; Sharath Chandra, S.P. Biological and ecological impact of iron and iron nanoparticles across diverse array of fish models: a review. Ecology, Environment and Conservation, 2020, 26, 180184,http://www.envirobiotechjournals.com/article_abstract.php?aid=10315\&iid=298\&jid=3.

7. Sharath Chandra, S.P.; Raghava,B.; Sharada, A.C. Synthesis, Characterisation, Molecular property prediction and Antipsychotic activity of Novel 6-fluoro-3-(piperidin-4-yl) benzo[d]isoxazole Derivatives. Int. J. Pharm. Sci. Rev. Res., 2014; 29, 302-308.

8. Hosoba, M.; Oshita, K.; Katarina, R.K.; Takayanagi, T.; Oshima, M.; Motomizu, S. Synthesis of novel chitosan resin possessing histidine moiety and its application to the determination of trace silver by ICP-AES coupled with triplet automated-pretreatment system. Anal. Chim. Acta 2009, 639, 51-56, https://doi.org/10.1016/j.aca.2009.02.050.

9. Wang, Y.; Ma, X.; Li, Y.; Li, X.; Yang, L.; Ji, L.; He, Y. Preparation of a novel chelating resin containing amidoxime-guanidine group and its recovery properties for silver ions in aqueous solution. Chem. Eng. J. 2012, 209, 394-400, https://doi.org/10.1016/j.cej.2012.07.143.

10. Perva, S.; Swamy, K.; Chandrashekar, N.; Subramanian, R.; Sukumaran, S.; Chandra S P, S. Physiobiochemical responses of Indian major carp Catla catla upon sub-chronic exposure to tin oxide nanoparticles. Egyptian Journal of Aquatic Biology and Fisheries 2020, 24, 509-520, https://doi.org/10.21608/ejabf.2020.102144.

11. Sun, H.; Zhang, X.; Niu, Q.; Chen, Y.; Crittenden, J.C. Enhanced Accumulation of Arsenate in Carp in the Presence of Titanium Dioxide Nanoparticles. Water, Air, Soil Pollut. 2007, 178, 245-254, https://doi.org/10.1007/s11270-006-9194-y.

12.AshaRani, P.V.; Low Kah Mun, G.; Hande, M.P.; Valiyaveettil, S. Cytotoxicity and Genotoxicity of Silver Nanoparticles in Human Cells. ACS Nano 2009, 3, 279-290, https://doi.org/10.1021/nn800596w.

13. Sfriso, A.A.; Mistri, M.; Munari, C.; Moro, I.; Wahsha, M.; Sfriso, A.; Juhmani, A.-S. Hazardous effects of silver nanoparticles for primary producers in transitional water systems: The case of the seaweed Ulva rigida C. Agardh. Environ. Int. 2019, 131, 104942, https://doi.org/10.1016/j.envint.2019.104942.

14. Pham, T.-L. Effect of silver nanoparticles on tropical freshwater and marine microalgae. Journal of Chemistry 2019, 2019, https://doi.org/10.1155/2019/9658386.

15. F. Gonçalves, S.; D. Pavlaki, M.; Lopes, R.; Hammes, J.; Gallego-Urrea, J.A.; Hassellöv, M.; Jurkschat, K.; Crossley, A.; Loureiro, S. Effects of silver nanoparticles on the freshwater snail Physa acuta: The role of test media and snails' life cycle stage. Environ. Toxicol. Chem. 2017, 36, 243-253, https://doi.org/10.1002/etc.3532. 
16. Lekamge, S.; Miranda, A.F.; Ball, A.S.; Shukla, R.; Nugegoda, D. The toxicity of coated silver nanoparticles to Daphnia carinata and trophic transfer from alga Raphidocelis subcapitata. PLoS One 2019, 14, e0214398, https://doi.org/10.1371/journal.pone.0214398.

17. Lekamge, S.; Miranda, A.F.; Abraham, A.; Li, V.; Shukla, R.; Bansal, V.; Nugegoda, D. The toxicity of silver nanoparticles (AgNPs) to three freshwater invertebrates with different life strategies: Hydra vulgaris, Daphnia carinata, and Paratya australiensis. Frontiers in Environmental Science 2018, 6, 152 , https://doi.org/10.3389/fenvs.2018.00152.

18. Chandra, S.; Sukumaran, S. Physiological, Biochemical and Neurochemical responses of Cirrhinus mrigala upon short term exposure to Cerium oxide. International Journal Of Aquatic Biology 2019, 7, 368-373.

19. Sharath Chandra, S.P.; Sukumaran, S. Magnesium chloride impairs physio-biochemical and neurochemical responses in cirrhinusmrigala (Hamilton, 1822) upon short term exposure. Biointerface Research in Applied Chemistry 2020, 10, 4934-4938, https://doi.org/10.33263/BRIAC101.934938.

20. Chandra, S.P.; Puneeth, H.R.; Mahadimane, P.V.; Sharada, A.C. Biochemical Evaluation of Cordia dichotoma Seed Extracts. Advanced Science Letters 2017, 23, 1823-1825. https://doi.org/10.1166/asl.2017.8514.

21. Puneeth, H.R.; Chandra, S.S.P. A review on potential therapeutic properties of Pomegranate (Punica granatum L.). Plant Science Today 2020, 7, 9-16, https://doi.org/10.14719/pst.2020.7.1.619.

22. Vishwaprakash Mahadimane, P.; Sharath Chandra, S.P. Analyzing the phytochemical, anti-ulcer, anthelmentic and antioxidant potentials of Tabernaemontana dichotoma Roxb. ex wall seed extracts. Journal of natural remedies. 2020,20, 139-145, https://doi.org/10.18311/jnr/2020/24346.

23. Chandra, S.P.; Mahadimane P, V. Effect Of Novel Benzisoxazole Derivatives Against Ehrlich Ascites Carcinoma Cells In Swiss Albino Mice: Cytotoxic And Haematalogical Studies. International Journal of Pharmaceutical Sciences and Research 2015, 6, 3606. 